\title{
How Academia Resembles a Drug Gang
}

[LE blogs.Ise.ac.uk/impactofsocialsciences/2013/12/11/how-academia-resembles-a-drug-gang/

Academic systems rely on the existence of a supply of "outsiders" ready to forgo wages and employment security in exchange for the prospect of uncertain security, prestige, freedom and reasonably high salaries that tenured positions entail. Drawing on data from the US, Germany and the UK, Alexandre Afonso looks at how the academic job market is structured in many respects like a drug gang, with an expanding mass of outsiders and a shrinking core of insiders.

In 2000, economist Steven Levitt and sociologist Sudhir Venkatesh published an article in the Quarterly Journal of Economics about the internal wage structure of a Chicago drug gang. This

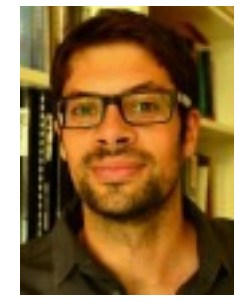
piece would later serve as a basis for a chapter in Levitt's (and Dubner's) best seller Freakonomics. The title of the chapter, "Why drug dealers still live with their moms", was based on the finding that the income distribution within gangs was extremely skewed in favor of those at the top, while the rank-and-file street sellers earned even less than employees in legitimate low-skilled activities, let's say at McDonald's. They calculated $\$ 3.30$ as the hourly rate, that is, well below a living wage (that's why they still live with their moms).

If you take into account the risk of being shot by rival gangs, ending up in jail or being beaten up by your own hierarchy, you might wonder why anybody would work for such a low wage and at such dreadful working conditions instead of seeking employment at McDonald's. Yet, gangs have no real difficulty in recruiting new members. The reason for this is that the prospect of future wealth, rather than current income and working conditions, is the main driver for people to stay in the business: low-level drug sellers forgo current income for (uncertain) future wealth. Rank-and file members are ready to face this risk to try to make it to the top, where life is good and money is flowing. It is very unlikely that they will make it (their mortality rate is insanely high) but they're ready to "get rich or die trying".

With a constant supply of new low-level drug sellers entering the market and ready to be exploited, drug lords can become increasingly rich without redistributing their wealth towards the bottom. There is an expanding mass of rankand-file "outsiders" ready to forgo income for future wealth, and a small core of "insiders" securing incomes largely at the expense of the mass. We can call it a winner-take-all market.

\section{Academia as a Dual Labour Market}

The academic job market is structured in many respects like a drug gang, with an expanding mass of outsiders and a shrinking core of insiders. Even if the probability that you might get shot in academia is relatively small (unless you mark student papers very harshly), one can observe similar dynamics. Academia is only one example of this trend, but it affects labour markets virtually everywhere. An important topic of research for labour market scholars at the moment is what we call "dualisation". Dualisation is the strengthening of this divide between insiders in secure, stable employment and outsiders in fixed-term, precarious employment. Academic systems more or less everywhere rely at least to some extent on the existence of a supply of "outsiders" ready to forgo wages and employment security in exchange for the prospect of uncertain security, prestige, freedom and reasonably high salaries that tenured positions entail. 


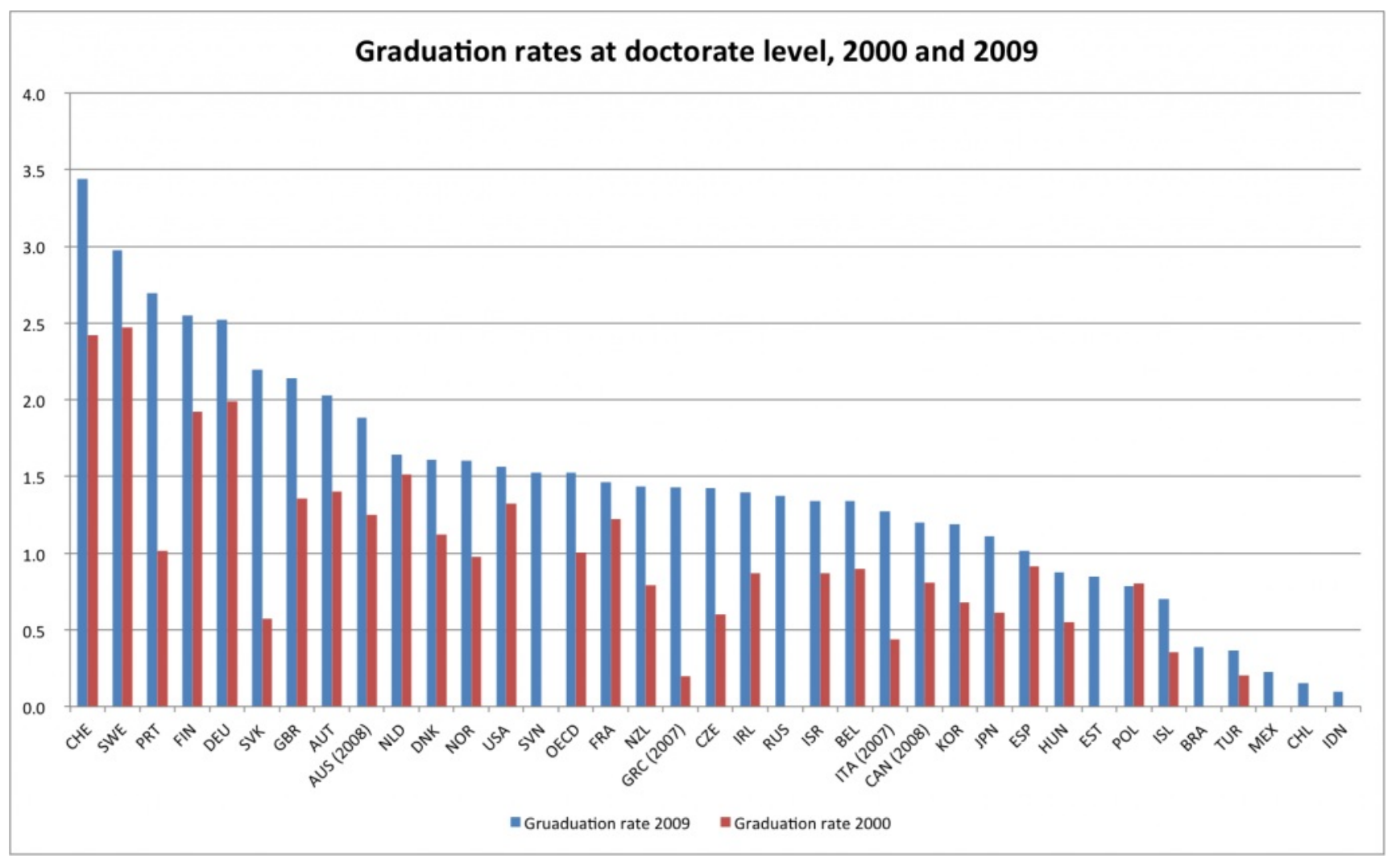

Figure 1. Source: OECD

How can we explain this trend? One of the underlying structural factors has been the massive expansion in the number of PhDs all across the OECD. Figure 1 shows the proportion of PhD holders as a proportion of the corresponding age cohort in a number of OECD countries at two points in time, in 2000 and 2009. As you can see, this share has increased by about $50 \%$ in 9 years, and this increase has been particularly pronounced in countries such as Portugal, Greece or Slovakia, where it nearly tripled, however from a low starting level. Even in countries with an already high share, the increase has been substantial: $60 \%$ in the UK, or nearly $30 \%$ in Germany. Since 2000 the number of OECD-area doctorates has increased at an average of $5 \%$ a year.

So what you have is an increasing number of PhD graduates arriving every year into the market hoping to secure a permanent position as a professor and enjoying freedom and - reasonably - high salaries, a bit like the rank-andfile drug dealer hoping to become a drug lord. To achieve that, they are ready to forgo the income and security that they could have in other areas of employment by accepting insecure working conditions in the hope of securing jobs that are not expanding at the same rate. Because of the increasing inflow of potential outsiders ready to accept this kind of working conditions, this allows insiders to outsource a number of their tasks onto them, especially teaching, in a context where there are increasing pressures for research and publishing. The result is that the core is shrinking, the periphery is expanding, and the core is increasingly dependent on the periphery. In many countries, universities rely to an increasing extent on an "industrial reserve army" of academics working on casual contracts because of this system of incentives.

\section{Varieties of Dualisation}

The developments outlined above are broad dynamics that span across almost all advanced industrial countries. However, the boundary of the insider and outsider group varies across countries, for instance between the United States, Germany and Britain.

In the United States, numbers from the department of education reported in The Atlantic (Figure 2 below) show that more than $40 \%$ of teaching staff at universities are now part-time faculty without tenure, or adjunct lecturers paid per 
course given, with no health insurance or the kind of other things associated with a standard employment relationship. As you can see from the graph, the share of permanent tenured faculty has shrunk dramatically. This doesn't mean that the absolute number of faculty has diminished, it has actually increased substantially, but it has been massively outpaced by the expansion of teaching staff with precarious jobs and on low incomes. The Chronicle of Higher Education recently reported about adjunct lecturers relying on food stamps. The person mentioned in the article declares a take-home pay of $\$ 900$ per month, which is sadly not that far away from the $\$ 3$ hourly rate of the drug dealer, but for a much more skilled job.

\section{FIGURE 1}

Trends in Instructional Staff Employment Status, 1975-2011

All Institutions, National Totals

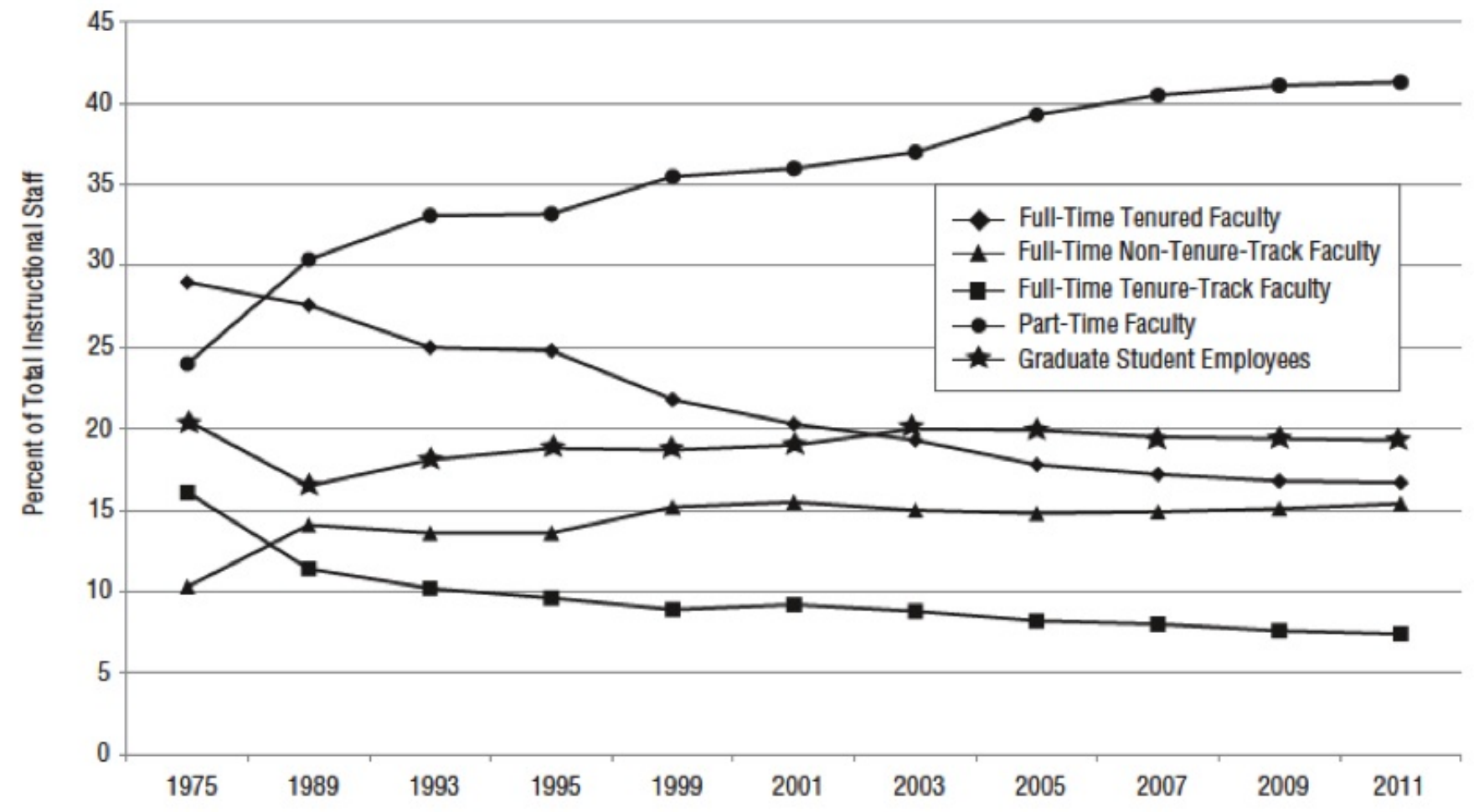

Notes: Figures for 2011 are estimated. Figures from 2005 have been corrected from those published in 2012. Figures are for degree-granting institutions only, but the precise category of institutions included has changed over time. Graduate student employee figure for 1975 is from 1976 . Percentages may not add to 100 due to rounding.

Source: US Department of Education, IPEDS Fall Staff Survey.

Figure 2. Source: American Association of University Professors

Germany is another case where there has traditionally been a strong insider-outsider divide, essentially because of the hourglass structure of the academic job market. On the one hand, there are relatively good conditions at the bottom at the PhD level, and opportunities have expanded recently because of massive investments in research programs and doctoral schools generating a mass of new very competitive PhDs. On the other hand, there are good jobs at the top, where full professors are comparatively well paid and have a great deal of autonomy. The problem is that there is nothing in the middle: for people who just received their $\mathrm{PhD}$, there is just a big hole, in which they have to face a period of limbo in fixed-term contracts (wissenschaftliche Mitarbeiter) or substitute professor (Vertretungsprofessur) for a number of years, after which they can hope to get their first permanent job in their mid40s, while this could happen ion their mid-30s in the 1970s.

Figure 3 shows the average age of the PhD, for the habilitation and the first professorship in political science between the 1970s and 1990s. The age of the PhD hasn't changed substantially but the age of the first 
professorship has increased by about 5 years. Also, it must be taken into account that there is a selection effect: the people in the sample are only those who have made it to the professorship, and it does not take into account all of those that have dropped out during the academic limbo. A number or new types or positions in the middle, such as the Juniorprofessuren have ben created, but most of them are also limited in time and are therefoe not the equivalent of tenure-track positions. Germany is the country of financial prudence, and both regional and federal governments have been reluctant to commit to fund programs and positions on a permanent basis.

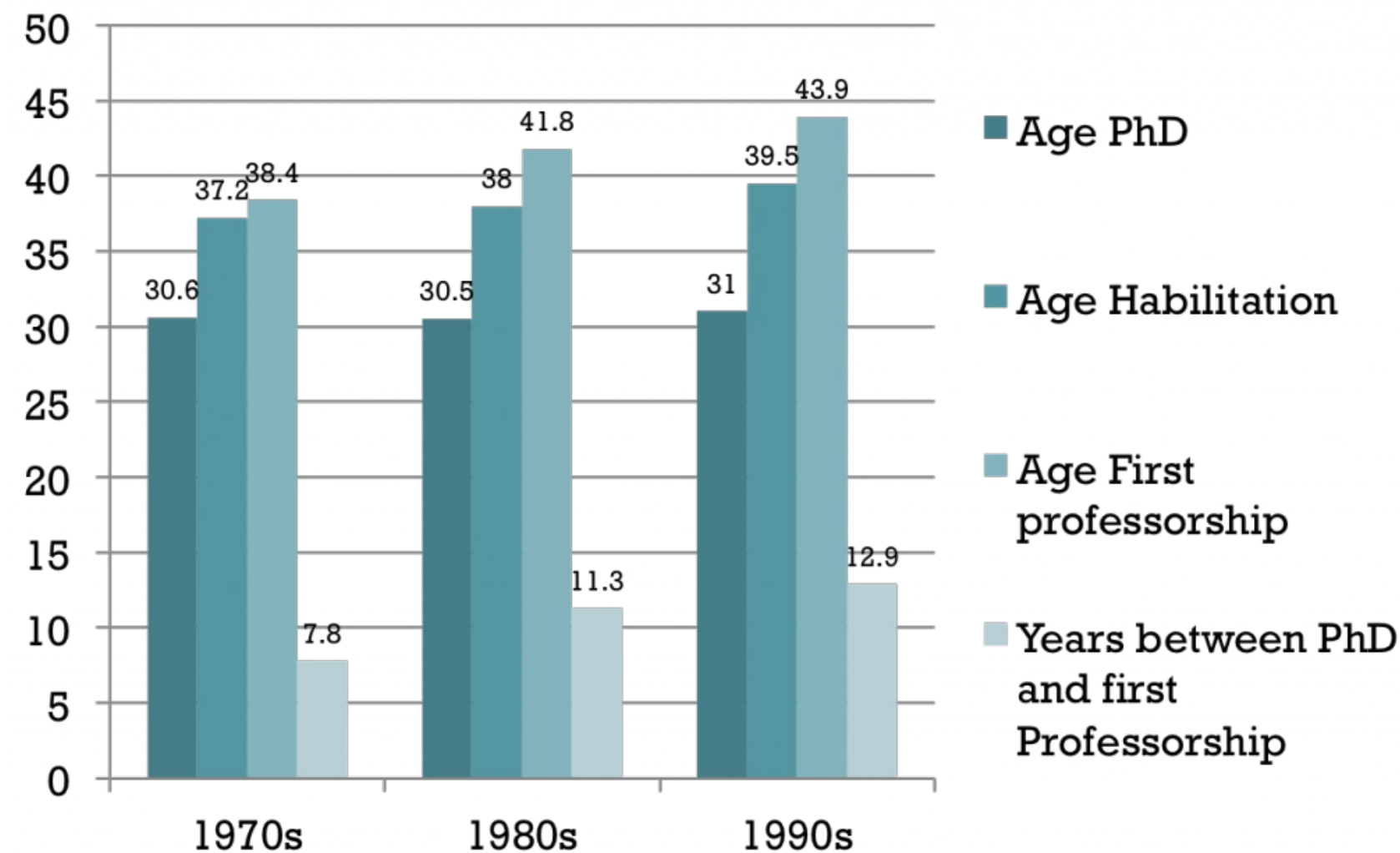

Figure 3. Source: Arendes, C., and H. Buchstein (2004): 22

This academic limbo is accentuated by the fact that in some disciplines, it has become common for tenured professors to apply for professorships in order to negotiate their own working conditions with their own university. The result of this is that it is very difficult for recent PhDs to compete with established professors, and hiring processes tend to last a very long time as many candidates refuse and take time to bargain back and forth. The main problem of this practice is time, that academics in permanent positions have but outsiders don't have. You cannot wait two years when a university is negotiating with somebody who will eventually refuse if you are on a fixed-term contract. This is a really perverse and insider-oriented system, especially as the period after the PhD is also often the one when individuals start a family.

The United Kingdom differs from Germany in the sense that it does have intermediate permanent positions for people finishing their $\mathrm{PhD}$. Britain is the biggest academic market in Europe and lectureships provide secure employment for relatively young academics even if the starting salary is somewhat lower than elsewhere if you take into account living costs, especially in London. However, this does not mean that British higher education does not rely on a large industrial workforce of outsiders as well. Recently, the Guardian reported on the prevalence of so called "zero-hour contracts" at UK universities. These are contracts which do not specify the number of hours a teacher/researcher is supposed to give, and basically imply that the workers needs to be available to her employer when there is work. Compared to Continental Europe, what is striking is the much more precarious employment situation of PhD students and teaching assistants, who provide a large part of the teaching of British universities, and whose employment conditions are much more casual than what one can see elsewhere. To give an example, 
when I did my PhD in Switzerland, I was basically a public employee paid to teach with a corresponding salary, pension contributions, welfare entitlements. A large proportion of PhD students in the UK do not have regular sources of funding, need to apply here and there to get scholarships, and when they teach, they are paid per hour taught or a piece rate (exam/essay marked) that can vary across and even within universities.

The number of hours usually taught at UK universities is relatively moderate, at least at Russell-Group universities, because of a heavier focus on essays and independent work from students, but also partly because departments can rely on this flexible workforce. This has been accentuated by the strong constraints set on universities in terms of research and publication through the REF (Research Excellence Framework). This happens through two channels. First, as research is what is most valued, this creates incentives for established professors to retreat from teaching and secure research grants and publications instead, leaving teaching to casual teaching staff. On the other hand, some universities have advertised a number of temporary positions just because of the REF in order to use people's publications in their submissions. There is no guarantee that universities are going to keep these people once they have "used" them.
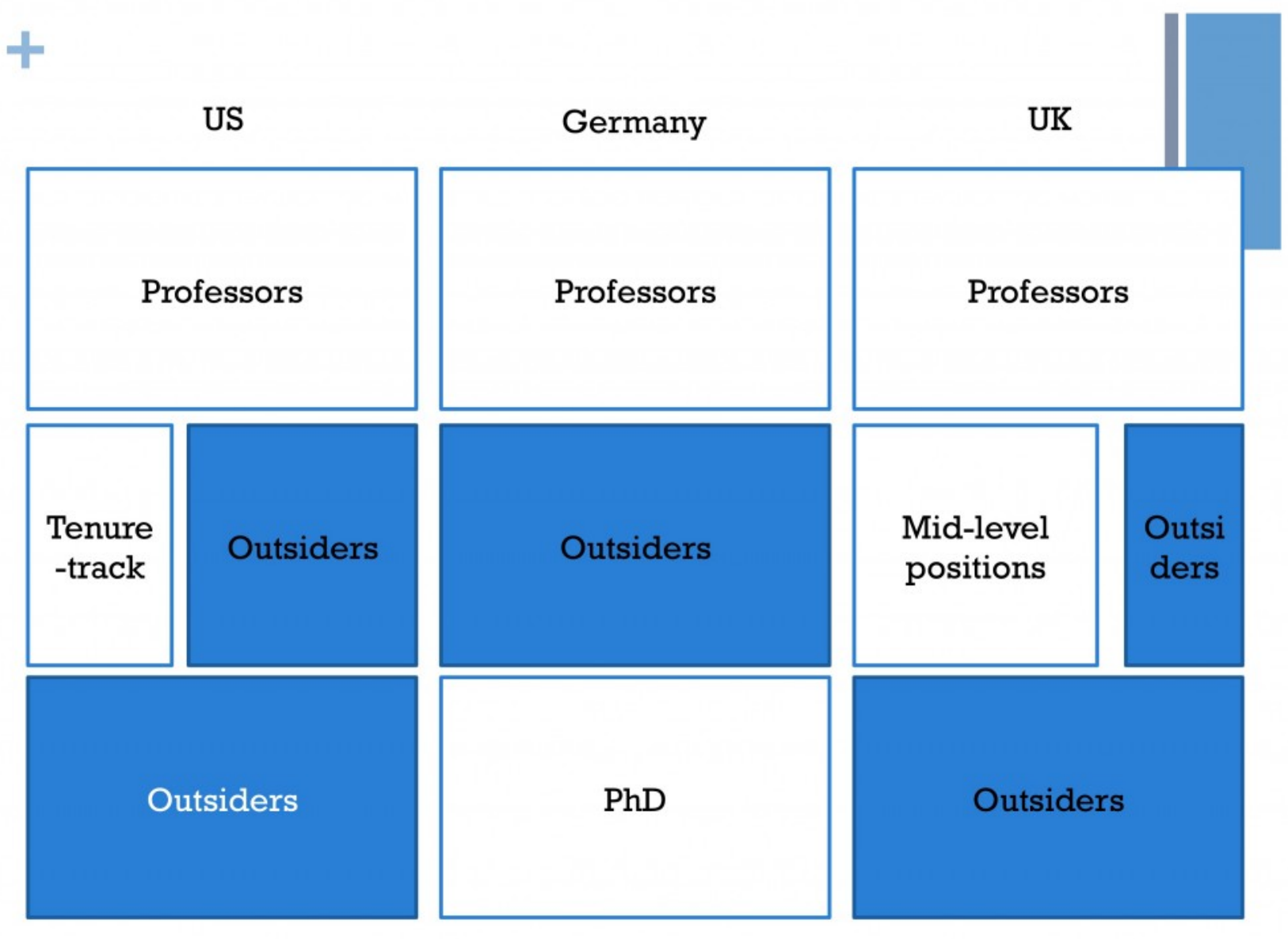

Figure 4 summarizes in broad terms the differences outlined above. As I can see it, this form of insider/outsider divide exists everywhere and is probably expanding. The interesting thing is that these divides are largely structural in the sense that the system simply could not work without this large supply of outsiders ready to accept any kind of employment contract. If you are mobile, strategic and concerned with employment conditions, you might want to exploit these differences and avoid the outsider boxes at different stages of your career. This would mean avoiding the UK for your PhD and avoiding Germany after your PhD. Of course, the employment status is not the only element to take into account, but "prestige" or "learning" are too often used to justify bad employment conditions by 
tenured faculty or ever more powerful university administrators.

Previous versions of this paper have been presented on November 19 at the European University Institute's Academic Careers Observatory Conference, and posted on Alexandre Afonso's Blog.

Note: This article gives the views of the author, and not the position of the Impact of Social Science blog, nor of the London School of Economics. Please review our Comments Policy if you have any concerns on posting a comment below.

\section{About the Author}

Alexandre Afonso is Lecturer in Comparative Politics in the Department of Political Economy at King's College London. His main areas of research are welfare state reforms, labour market policies, labour migration policies and the role of parties and organized interests in these domains. Twitter @alexandreafonso

- Copyright $($ The Author (or The Authors) - Unless otherwise stated, this work is licensed under a Creative Commons Attribution Unported 3.0 License. 